\title{
As percepções e os significados para os estagiários de Educação Física em relação à indisciplina na escola
}

\author{
Ivan Luis dos Santos* \\ Heitor de Andrade Rodrigues* \\ Fábio Tomio Fuzzi* \\ Ricardo Simões de Oliveira** \\ Mateus Kerr de Oliveira** \\ Daniela Fernanda Peluqui** \\ Suraya Cristina Darido***
}

\begin{abstract}
Resumo: Esta pesquisa buscou investigar as percepções e os significados para os estagiários de Educação Física em relação à indisciplina na escola. A metodologia utilizada foi de natureza qualitativa, tendo como participantes 16 alunos de um curso público de Licenciatura em Educação Física. A indisciplina foi apontada pelos estagiários como um problema presente em suas práticas e atrelado a diferentes dificuldades. Os informantes citaram como procedimentos mais comuns a chantagem, os combinados e o diálogo, sendo a instituição escolar destacada enquanto elucidadora das regras, dos direitos e dos deveres dos alunos.
\end{abstract}

Palavras-chave: Comportamento. Educação Física. Ensino fundamental e médio.

\section{INTRODUÇÃO}

Um dos problemas que mais afligem os educadores atualmente é o da indisciplina dos alunos, na medida em que aumentam os atos

\footnotetext{
* Mestrandos em Ciências da Motricidade. Departamento de Educação Física. Instituto de Biociências. UNESP, Campus de Rio Claro. Membros do Laboratório de Estudos e Trabalhos Pedagógicos em Educação Física (LETPEF). Rio Claro, SP. Brasil. E-mail: ivanls.santos @gmail.com

* Graduados no curso de Licenciatura em Educação Física. Instituto de Biociências. UNESP, Campus de Rio Claro. Membros do Laboratório de Estudos e Trabalhos Pedagógicos em Educação Física (LETPEF). Rio Claro, SP. Brasil. E-mail: triheitor@yahoo.com.br

**t Doutora em Educação Física. Professora do Departamento de Educação Física do Instituto de Biociências. UNESP, Campus de Rio Claro. Coordenadora do Laboratório de estudos e Trabalhos Pedagógicos em Educação Física (LETPEF). Rio Claro, SP. Brasil.

E-mail: surayacd@rc.unesp.br
} 
de agressão, violência, depredação e desrespeito. Embora seja constantemente mencionada, atingindo, às vezes, níveis alarmantes, a indisciplina no sistema escolar não possui um diagnóstico simples e as propostas de solução estão longe de serem alcançadas.

A indisciplina se faz presente tanto dentro da escola como fora dela, sendo um dos problemas que mais chamam a atenção dos educadores. Por exemplo, em pesquisa realizada por Gaspari et al. (2006) foi detectada que uma das maiores dificuldades dos professores de Educação Física refere-se à indisciplina, representando um impedimento à implantação de novas propostas educacionais.

Vale ressaltar também que, de acordo com Aquino (1996), a indisciplina atravessa indistintamente as escolas públicas e privadas, apesar dos diferentes significados atribuídos para a mesma. Portanto, ao contrário do que muitos pensam, não se trata de um "privilégio" da escola pública.

A indisciplina tem uma série de razões. Uma delas refere-se às dificuldades que, atualmente, muitos pais enfrentam em impor limites aos filhos. Na maioria dos casos, porque não permanecem tempo suficiente com os seus filhos e quando os vêem preferem não discutir. Além disso, vive-se uma crise de valores, sobretudo com a imposição de referenciais midiáticos, nos quais vale mais a aparência do que o conhecimento ou o engajamento social.

Outra razão possível para a indisciplina refere-se ao novo ritmo na vida dos meninos e das meninas, marcado pelas novas tecnologias. As imagens da TV são muito rápidas, os cortes são alucinantes, assim como os jogos de computadores e de vídeo-game. Dessa forma, quando chegam à escola - que continua com as mesmas aulas e formatos - os alunos estranham e reclamam.

Essa configuração se expressa em diferentes manifestações de mal-estar, em tensões e conflitos denunciados pelos estudantes. É o próprio horizonte utópico da escola que entra em questão: os desafios do mundo atual denunciam a fragilidade e a insuficiência dos ideais 'modernos' e passam a exigir e suscitar novas interrogações e buscas. A escola, nesse contexto, mais que a transmissora da

Movimento, Porto Alegre, v. 14, n. 03, p. 117-137, setembro/dezembro de 2008. 
cultura, da 'verdadeira cultura', passa a ser clamada enquanto um espaço de cruzamento, conflitos e diálogo com o 'mundo tecnológico'.

$\mathrm{Na}$ verdade, o tema da indisciplina é bastante complexo e delicado. É complexo porque envolve no mínimo duas dimensões: a política, das relações democráticas, penetrando em várias instituições, a destacar a família e a escola; e a ética, da falta de limites, que traduz uma crise de valores. É também delicado porque pode promover retrocessos na leitura do problema, trazendo à tona, novamente, um autoritarismo injustificável de tempos não muitos distantes.

La Taille (1996) define primeiramente a disciplina como comportamentos regidos por um conjunto de normas, desta maneira, traduz a indisciplina de duas formas, sendo a primeira a revolta contra estas normas e a segunda o desconhecimento delas. No primeiro caso, a indisciplina traduz-se em uma forma de desobediência insolente; no segundo caso, pelo caos dos comportamentos, pela desorganização das relações. Isto estaria sendo traduzido nas aulas como bagunça, tumulto, faltas de limites, maus comportamentos, desrespeito a figuras de autoridades, etc.

Dentre tantos problemas no trabalho escolar, a indisciplina discente destaca-se como uma queixa predominante entre os profissionais. A maioria dos professores, sejam eles recém formados ou experientes, considera a manutenção da disciplina como uma condição indispensável para o seu trabalho, o que se constitui em uma de suas primeiras preocupações. Para Pieron (1988), a direção de uma classe envolve numerosos aspectos de ensino, na qual a disciplina é, com freqüência, tida como um requisito fundamental. Para alguns teóricos, como Good e Brophy (1978), trata-se de uma questão que vai além de um simples problema metodológico, referindo-se a uma preocupação do dia-a-dia do professor em sua ação em sala de aula.

Aquino (1996), uma das grandes referências na discussão da indisciplina na escola, afirma que falar sobre o tema não é tarefa muito simples e que, além disso, não recebeu a devida atenção dos meios acadêmicos. Diante disso, pergunta-se: será que os profissionais da Educação, em particular os professores, estão recebendo no decurso de sua formação uma base consistente, que lhes sirva de apoio

Movimento, Porto Alegre, v. 14, n. 03, p. 117-137, setembro/dezembro de 2008. 
para lidar com a diversidade de comportamentos que irão encontrar em uma sala de aula?

No processo de aprendizagem, a disciplina em sala de aula é desejável e pode ser fruto apenas da boa educação, ou seja, possuir alguns modos de comportamento que permitam o convívio pacífico. Isto, no entanto, resume apenas a pura aparência, visto que o aluno bem comportado pode ser assim por medo do castigo ou por conformismo. Isto é desejável?

Na compreensão de Passos (1996), a indisciplina pode ser entendida como:

\footnotetext{
[...] um fogo que atravessa a calmaria e faz nascer novos movimentos, diversas imagens invertidas: um atravessamento na forma pela qual as escolas estão socialmente organizadas, passando por toda a normatização imposta pela instituição para dirigir-se a um aluno adulto e autônomo, que pode reconstruir conhecimentos (PASSOS, 1996, p. 33).
}

A discussão e reflexão proposta é que talvez se possa atribuir outros significados à indisciplina, como a ousadia, a criatividade, $o$ inconformismo e a resistência, que não estão diretamente ligados à negação da disciplina.

Segundo Marrach (2006), a reforma educacional ao longo dos anos resultou na queda de qualidade de ensino e da educação em geral. Além disso, os baixos salários e a desvalorização da profissão acarretam desmotivação do profissional e perda de respeito dos alunos. A autora ainda acrescenta que os conflitos sociais estão refletidos na escola. Isso significa que a violência, o preconceito, o nivelamento de classes, o uso de drogas, entre outros aspectos, influenciam diretamente no comportamento dos alunos.

Alves (2002) ressalta que o aluno não pode ser o único culpado pelo acontecimento da indisciplina, pois as questões sociais referentes à família, à instituição escolar, à política, à religiosidade ou a qualquer outro âmbito social também são fatores que contribuem para a ocorrência da mesma. A autora ainda considera que, se as propostas curriculares estabelecidas, a metodologia utilizada e a postura adotada

Movimento, Porto Alegre, v. 14, n. 03, p. 117-137, setembro/dezembro de 2008. 
pelo professor forem inadequadas ao contexto em que se insere, a possibilidade de surgir o comportamento indisciplinado será maior.

Na mesma linha de raciocínio, Aquino (1996) cita dois fatores determinantes da indisciplina escolar. O fator sócio-histórico, que pressupõe que a instituição escolar não acompanhou a evolução e a transformação de sua clientela (alunos), ou seja, "[...] a escola tem sido idealizada e gerida para um tipo de sujeito e é ocupada por outro" (AQUINO, 1996, p. 45). E o fator psicológico, que aponta para a necessidade do aluno introjetar determinados valores, anteriormente à escolarização, como permeabilidade às regras comuns, partilha de responsabilidades, cooperação e reciprocidade, que permitirão uma estruturação psicológica e moral para a convivência em grupo na sala de aula e o reconhecimento da autoridade externa, no caso, o professor.

Sendo assim, a indisciplina parece ser causada pela soma de diversas razões distribuídas igualmente entre a escola, família, desigualdade social, aluno e professor.

Com relação à Educação Física, a dinâmica das aulas, através de atividades ligadas aos conteúdos de jogos, esportes, danças, lutas e ginásticas maximizam os conflitos e as questões ligadas às atitudes e valores. Assim, surgem perguntas como: a indisciplina é um problema que também acomete os estagiários de Educação Física? E, ainda, como esses futuros professores compreendem os significados da indisciplina?

Não por outro motivo, o objetivo dessa pesquisa foi investigar as percepções e os significados para os estagiários de um curso público de Educação Física em relação à indisciplina na escola.

A escolha por ouvir estagiários de Educação Física remete-se ao fato destes encontrarem-se num momento de transição entre a Universidade e o campo de trabalho, num processo de adaptação e aprimoramento da formação profissional. Além disso, este é um período ao qual o graduando - futuro professor - vivencia novas experiências, conhecendo melhor sua área de atuação.

Logo, espera-se que o levantamento desses dados permita aos professores universitários, especialmente aos responsáveis pela disciplina de prática de ensino, condições de compreender e desvelar

Movimento, Porto Alegre, v. 14, n. 03, p. 117-137, setembro/dezembro de 2008. 
aspectos da formação profissional dos seus alunos, sobretudo no que diz respeito ao tema em questão.

\section{Metodologia}

A metodologia utilizada foi de natureza qualitativa e do tipo descritiva. Por meio dessa abordagem, procurou-se registrar, descrever, analisar e interpretar o discurso dos estagiários entrevistados.

$\mathrm{Na}$ análise de Triviños (1987), as pesquisas com enfoque qualitativo surgem em contraposição à atitude tradicional de aplicar aos estudos das ciências humanas os mesmos princípios e métodos das ciências naturais.

Na visão de Ludke e André (1986), com a evolução dos estudos na área educacional, percebeu-se que poucos fenômenos nessa área podem ser submetidos à abordagem analítica, típica das pesquisas experimentais, pois em Educação as coisas acontecem de maneira inextrincável e não é possível isolar as variáveis envolvidas.

A entrevista semi-estruturada foi a estratégia utilizada para a coleta dos dados descritivos na linguagem dos estagiários, permitindo desenvolver uma idéia sobre a maneira como esses interpretam aspectos do mundo. Dessa forma, possibilitou-se aos investigadores partirem de questionários básicos, apoiados em teorias e hipóteses e, com o decorrer da entrevista, aprofundar as interrogativas.

Esse tipo de técnica exige um respeito grande ao entrevistado, envolvendo desde local e horário marcados e cumpridos, até o total sigilo e preservação de identidade do informante, estabelecendo um clima de confiança para que o entrevistado se sinta à vontade para se expressar livremente (LUKDE; ANDRÉ, 1986).

Os participantes da pesquisa foram 16 alunos de um curso de Licenciatura em Educação Física de uma Universidade pública. Ao longo dos anos de 2005-2006, esses alunos, estagiários da disciplina Prática de Ensino, tiveram suas primeiras experiências como professores na Educação Básica, (mais especificamente, com os níveis de ensino Fundamental e Médio) enfrentando, assim, os inúmeros desafios da prática pedagógica.

Movimento, Porto Alegre, v. 14, n. 03, p. 117-137, setembro/dezembro de 2008. 
Ao longo das entrevistas, os pesquisadores tentaram apreender as percepções dos estagiários, bem como os significados atribuídos por estes em relação à indisciplina na escola. As entrevistas foram realizadas individualmente e apresentavam um total de oito questões, podendo ser ampliadas no transcorrer das respostas, a depender da necessidade de maiores esclarecimentos por parte do pesquisador. Foram elas: 1) Quais as principais dificuldades enfrentadas na prática de ensino? 2)Você tem problemas relacionados à indisciplina? Quais? Dê exemplo. 3) O que é indisciplina? 4) Quais os procedimentos/ estratégias que você utiliza para minimizar a indisciplina? 5) Tem diferença a indisciplina manifestada nas aulas de Educação Física em relação às demais disciplinas? 6) Qual o papel da escola diante da indisciplina? 7) Qual o papel da Educação Física diante da indisciplina? 8) Descreva o perfil de um aluno disciplinado. Concedeuse aos participantes o direito de escolha do local de realização da entrevista. O tempo médio de duração para cada uma delas foi de 30 minutos.

Os dados obtidos por meio da entrevista foram agrupados em categorias que permitiram uma compreensão mais detalhada dos resultados.

\section{RESULTADOS E DISCUSSÃO}

Os resultados apontaram que são inúmeros os enfrentamentos dos estagiários ao longo do tempo e espaço escolar, com um total de 22 motivos distintos. A indisciplina, a falta de interesse dos alunos e a resistência aos novos conteúdos foram os mais citados. Esses resultados corroboram com aqueles obtidos por Gaspari et al. (2006), que, ao entrevistarem professores de Educação Física do Ensino Fundamental e Médio, também identificaram a questão da indisciplina, bem como da falta de limites, como as principais dificuldades concernentes à prática pedagógica desses docentes. Ou seja, as dificuldades dos estagiários parecem ser as mesmas enfrentadas por professores formados.

Foram citadas como dificuldades relacionadas à indisciplina, a agitação excessiva, questões atreladas à falta de respeito, desobediência,

Movimento, Porto Alegre, v. 14, n. 03, p. 117-137, setembro/dezembro de 2008. 
falta de silêncio e dificuldade de atenção dos alunos. Na fala de um dos estagiários: "[...] eles só querem saber de conversar, pode ficar quinze minutos lá na frente sem falar nada, eles não percebem que você está querendo falar" (ESTAGIÁRIO 7).

Outro dado que parece relevante é que há entre os estagiários a percepção de que, no Ensino Médio, a adesão às aulas constitui-se como o maior problema, enquanto que, no Ensino Fundamental, a principal dificuldade diz respeito aos aspectos relacionados às atitudes dos alunos: conversas paralelas, brigas, desatenção e etc.

Diante do exposto, os dados foram agrupados em duas categorias. A primeira categoria buscou compreender a concepção e as manifestações de indisciplina na prática dos estagiários, além do referencial que esses possuem ao descreverem o perfil de um aluno disciplinado. E, num segundo momento, as causas da indisciplina, o papel da escola frente a ela, bem como alguns procedimentos metodológicos adotados pelos estagiários com vistas à superação dessas dificuldades. Para cada uma das categorias apresentamos aspectos comuns e divergentes entre os estagiários, confrontando as respostas com outros estudos, além de disponibilizarmos exemplos das falas dos participantes.

\subsection{O QUE É INDISCIPINA, ALUNO DISCIPLINADO E COMO ELA SE MANIFESTA}

Os estagiários, ao serem questionados a respeito do que entendiam como indisciplina, citaram ações presentes ou ausentes no comportamento dos alunos que, segundo eles, indicam um comportamento indisciplinado. Nenhum deles citou explicitamente uma definição sobre indisciplina. Todos se restringiram a oferecer exemplos de comportamentos indisciplinados. Um dos estagiários não respondeu a pergunta, argumentando que:

Não sei conceituar ou classificar o que é indisciplina, porque dá pra encarar por vários ângulos diferentes. A questão da indisciplina não é mais que os valores morais dos próprios professores. Mais do que a intenção da criança em te ofender, você deve entender o motivo da criança, porque ela está te tratando daquela forma, e não encarar previamente aquilo como ato de indisciplina. Temos várias regras pra

Movimento, Porto Alegre, v. 14, n. 03, p. 117-137, setembro/dezembro de 2008. 
classificar o que é indisciplina, "Indisciplina é isso!". Eu não tenho modelo restritivo pra classificar o que é indisciplina. Complicado (ESTAGIÁRIO 15).

O comportamento mais citado (11 vezes) relacionado à indisciplina foi referente ao fato dos alunos não seguirem regras pré-determinadas. Nesse sentido, um dos respondentes apontou que: "[...] Acho que são atitudes que vão contra regras estabelecidas. Se você não está dentro das regras, isso significa que você é uma pessoa não disciplinada" (ESTAGIÁRIO 6).

Também compreendeu-se indisciplina como falta de respeito ao professor, aos colegas e aos estagiários: "[...] Posso considerar como uma falta de respeito para com os outros colegas e para com o professor da classe, ou no momento com o estagiário" (ESTAGIÁRIO 14).

Só faz sentido falar em indisciplina se considerarmos a vida em conjunto, em coletivo, que adota algumas regras e princípios básicos para tornar a convivência possível. O rompimento com a disciplina estaria, então, relacionado ao descumprimento dessas regras. Podese considerar também que, num Estado democrático de direito, as regras regentes seriam as da democracia que deve, necessariamente, garantir a dignidade da pessoa humana, a igualdade de direitos, a participação e o conceito-responsabilidade pela vida social.

Pela não elucidação da necessidade de garantia desses princípios é que muitas professoras e professores sofrem com o problema da indisciplina em suas aulas. Por isso, seus alunos e alunas passam a não ter a noção real do significado, do respeito aos direitos humanos, do repúdio à discriminação, dado a inexistência de clareza sobre esses assuntos. Dessa maneira, não se consegue manter o respeito mútuo nas relações interpessoais, sejam elas públicas ou privadas, por não se conhecer outro tipo de relação possível, que não a individualista, que busca a vantagem e posse ao invés da convivência e construção.

Analisando por essa perspectiva, é possível compreender o abandono das regras e a falta de respeito por parte dos alunos. As regras construídas de qualquer outra maneira, que não coletivamente, não deixam transparecer sua finalidade coletiva. O respeito é exigido

Movimento, Porto Alegre, v. 14, n. 03, p. 117-137, setembro/dezembro de 2008. 
por imposição e não pela demonstração da valorização do outro e de seu espaço.

Ao descreverem o perfil de um aluno disciplinado, com 9 citações, o mais lembrado pelos respondentes se refere ao perfil de aluno não passivo, ou seja, o aluno que conversa, faz bagunça, não fica quieto, fala, não engole tudo, questiona, critica, brinca, dá opiniões. Nesse sentido, fica claro que os participantes dessa pesquisa não utilizam as referências da escola tradicional no que diz respeito ao conceito de aluno disciplinado.

Outro termo bastante utilizado pelos respondentes, num total de 8 citações, refere-se à necessidade dos alunos disciplinados apresentarem respeito. Respeito pelas regras, pelo professor e pelos demais alunos, reforçando o conceito atribuído por eles à indisciplina.

Interessante notar que todos os estagiários disseram vivenciar manifestações de indisciplina em suas aulas. Dentre os exemplos, o ato de xingar foi o mais lembrado, sendo citado por 8 dos 16 participantes: "Têm alguns alunos que em todas as matérias, a gente conversa com os outros professores, e eles têm problemas de indisciplina. Os alunos batem nos coleguinhas, xingam, ofendem, você pede pra sentar e não senta. Falta de educação mesmo" (ESTAGIÁRIO 7).

A seguir, as situações mais citadas, por 5 dos 16 entrevistados, foram as brigas entre os alunos, a falta de obediência dos mesmos e a falta de respeito tanto com colegas quanto com professores, conforme ilustram os depoimentos a seguir: $[\ldots]$ o que mais vejo são xingamentos, empurrões
mais agressivos. Mas não sai sangue, ou alguém
que se machuque (ESTAGIÁRIO 15).

Você fala com um menino e ele não dá a bola pra você, você pede a bola, ele te xinga e não dá, vira e joga a bola longe (ESTAGIÁRIO 13).

Os exemplos citados são algumas situações com as quais os estagiários se depararam durante suas aulas. Aquino (1996), a partir de relatos de professores, aponta que a questão da disciplina dos alunos é hoje uma das dificuldades fundamentais quanto ao trabalho escolar. Segundo ele, a conduta desordenada dos alunos como bagunça,

Movimento, Porto Alegre, v. 14, n. 03, p. 117-137, setembro/dezembro de 2008. 
tumulto, falta de limites, maus comportamentos, desrespeito às figuras de autoridade etc., são obstáculos centrais.

\subsection{ESCOLA, EDUCAÇÃO FÍSICA E INDISCIPLINA, SUAS CAUSAS E OS} PROCEDIMENTOS METODOLÓGICOS UTILIZADOS PELOS ESTAGIÁRIOS

Buscou-se verificar a concepção do entrevistado sobre o papel da escola diante da indisciplina. Assim, esperavam-se respostas que contemplassem a complexidade dos aspectos que constituem e definem a escola em nossa sociedade. No âmbito da análise, foi possível identificar três grandes blocos de respostas.

O primeiro bloco, com 6 citações, identifica o papel da escola como sendo o de mostrar aos alunos as regras, os direitos e os deveres dentro e fora da escola. Nesse mesmo bloco, metade dos entrevistados acredita que o meio para se alcançar esse objetivo seja a punição, já outra metade acredita que o meio mais eficaz seja a conscientização. Abaixo, podemos observar a visão de dois participantes da pesquisa:

\footnotetext{
Dependendo do tipo de indisciplina deve punir. Aí depende do objetivo da escola. Fazer com que o aluno tente ver que o que ele fez não é certo, não foi decidido pelo grupo, não está adequado (ESTAGIÁRIO 2).

Eu acho que esse é o papel da escola, formar o cidadão, então, que ensine a respeitar os outros e a si mesmo, assim como os limites, direitos e deveres. Que mostre ao aluno como ser ponderado e a ter uma consciência na hora que ele tem que fazer as coisas (ESTAGIÁRIO 8).
}

De acordo com o documento de temas transversais (BRASIL, 1998), não se trata de impor valores, mas sim afirmá-los através da coerência dos valores assumidos, possibilitando aos alunos a discussão sobre eles e a construção de critérios para escolha pessoal.

Na compreensão de Rego (1996) as normas devem deixar de serem vistas como elementos castradores. A escola precisa trabalhar com regras e normas que orientem o convívio escolar, de maneira a serem compreendidas como uma condição necessária ao convívio social.

Movimento, Porto Alegre, v. 14, n. 03, p. 117-137, setembro/dezembro de 2008. 
No segundo bloco, com 4 citações, foi possível agrupar as respostas daqueles que acreditam ser o papel da escola frente à indisciplina, preocupar-se com os interesses e necessidades das crianças e adolescentes, ajustando sua estrutura, planejamento e intervenção às ambições e anseios dos alunos: "A escola tem que reestruturar seu papel de educação no processo educacional. Têm que voltar seus interesses, os seus significados aos valores da criança" (ESTAGIÁRIO 15).

Aquino (1996) afirma, nessa mesma linha de raciocínio, que o trabalho educacional passa a não ser apenas de transmissão ou mediação das informações, mas de (re)invenção do modo de tratá-las.

Em um terceiro bloco, com cinco citações, visualiza-se o papel da escola como sendo o de estabelecer uma relação mais íntima entre a própria instituição e os pais de alunos. Para os estagiários, aproximar os familiares do convívio escolar significa dar condições para a efetivação de um trabalho em conjunto, rumo a tentativa de solução do problema.

Na compreensão desse grupo, diminuir a indisciplina não é papel apenas da escola, mas um esforço cooperativo, como podemos identificar no relato: "A escola deveria ter um papel no trabalho junto com os pais, de aprender a ter relacionamento. A criança precisa aprender a se relacionar" (ESTAGIÁRIO 3).

Aquino (1996) concorda com os entrevistados na medida em que aponta que a Educação não é de responsabilidade exclusiva da escola. Nesse sentido, a estruturação escolar não poderá ser pensada apartada da família.

Especificamente com relação à Educação Física, dentre os 16 estagiários entrevistados, 13 apontaram que a indisciplina nas aulas de Educação Física é diferente daquela apresentada nas demais disciplinas. Identificamos, basicamente, dois grandes grupos de respostas que buscaram justificar tal entendimento. $\mathrm{O}$ primeiro diz respeito à maior liberdade dada aos alunos durante as aulas de Educação Física:

Você estando na quadra é um espaço muito aberto. Na sala de aula, todos, querendo ou não, estão olhando para o professor, sentados, quietos. A quadra é

Wovimento, Porto Alegre, v. 14, n. 03, p. 117-137, setembro/dezembro de 2008. 
um lugar mais amplo, então, você chega e já vai cada um para um canto... eles estão livres, seus corpos estão livres (ESTAGIÁRIO 3).

Semelhante argumento foi levantado por Impolcetto (2000), que também atribui a dificuldade de domínio da turma pelo professor ao fato das aulas de Educação Física serem realizadas em espaço aberto, facilitando, assim, a dispersão dos alunos.

Neste grupo, localizam-se alguns discursos que, concomitantemente e em conseqüência à questão da liberdade, indicaram como possíveis intensificadores da indisciplina nas aulas de Educação Física os seguintes argumentos: o aumento do contato físico e da agressividade entre os alunos, a necessidade de se gastar energia por parte dos mesmos, os gritos em detrimento ao murmúrio do ambiente de classe e a dificuldade de controle da classe por parte dos professores.

Um segundo grupo de respostas que buscou justificar a especificidade da indisciplina nas aulas de Educação Física, fez relação à identidade dessa disciplina, enquanto componente curricular do Ensino Básico, bem como a compreensão de seus objetivos por parte dos alunos. De acordo com um dos estagiários: "A imagem que os alunos têm de nossa área dificulta um pouco. Eles acham que é só uma área prática, que a Educação Física é dar a bola, é quadra" (ESTAGIÁRIO 8).

Na sala, ao que nos parece, o ambiente delimitado por quatro paredes, carteiras enfileiradas e a presença de um professor, estrategicamente posicionado à frente da classe, transmite a falsa perspectiva de disciplina. Na verdade, a imposição de valores e "comportamentos adequados" alimentados por essa estrutura escolar, contraria o princípio democrático de liberdade e, principalmente, difere da perspectiva da autonomia na construção moral do aluno (BRASIL, 1998).

O termo "liberdade", enquanto elemento básico do princípio democrático está intimamente relacionado à afirmação de valores que garantem a todos o direito a ter direitos (BRASIL, 1998). Entretanto, nas aulas de Educação Física, ele é confundido com a ausência de limites, sejam eles, físicos, atitudinais ou de reconhecimento da figura do professor. Tais pressupostos estariam reforçados pelo fato do

Movimento, Porto Alegre, v. 14, n. 03, p. 117-137, setembro/dezembro de 2008. 
saber das aulas de Educação Física, na maioria das vezes, ser visto como algo possuidor de pouco ou nenhum valor para as crianças e adolescentes, fundamentando a idéia apontada pelos temas transversais dos Parâmetros Curriculares Nacionais (BRASIL, 1998) que, dentro de uma sociedade, valores diferentes fundamentam interesses e comportamentos diversos.

No que se refere as possíveis causas da indisciplina, para 8 dos 16 entrevistados, a indisciplina dos alunos ocorre em função da Educação que receberam dentro de casa, na família. Esse grupo acredita que a base familiar está afetada, que a figura dos pais não representa respeito e autoridade, e a educação dos seus filhos é livre demais, com conseqüências no comportamento dos alunos: "É uma serie de fatores que influenciam, um é a educação em casa, se ele não respeita o pai, não é a figura do professor que ele vai respeitar. Se está acostumado a desobedecer ao pai, não vai obedecer ao professor que é menos que o pai dele" (ESTAGIÁRIO 4).

Um olhar psicológico, a questão da indisciplina estaria associada à idéia de uma carência psíquica do aluno. Essa carência de uma infra-estrutura psicológica e moral vem antes da escolarização. Aquino (1996) afirma que esta estrutura psíquica é, primordialmente, de responsabilidade da família, sendo assim, a estruturação escolar não poderá ser pensada separada da familiar. Ou seja, o processo educacional depende da articulação desses dois âmbitos institucionais que se complementam, mas não se justapõem.

Outro aspecto a ser destacado diz respeito à percepção dos estagiários em relação às motivações que levam os alunos a adotarem comportamentos indisciplinados. $\mathrm{O}$ fato mais vezes mencionado pelos entrevistados, com 5 citações, foi o tempo de permanência excessivo ao qual esses alunos permanecem em sala, parados e sentados na carteira, sendo a aula de Educação Física, sinônimo de "liberdade":

\footnotetext{
Eu acho que eles ficam muito tempo sentados, várias horas, são pequenos, a gente está trabalhando com 6 e 7 anos, quando eles saem da sala, eles querem ficar correndo, se movimentando e a gente tem que explicar a atividade, então tem dificuldade deles pararem (ESTAGIÁRIO 9).
}

Movimento, Porto Alegre, v. 14, n. 03, p. 117-137, setembro/dezembro de 2008. 
Assim, poderíamos pensar na necessidade de uma nova escola, capaz de ultrapassar a linguagem da imobilidade e do silêncio. Nesse sentido, questionou Freire (1997):

Não haveria uma outra forma de ensinar que não fosse mantendo os alunos presos às carteiras, silenciosos, imóveis? Aluno só aprende sentado e sem fazer barulho? [...] de minha parte estou convicto que só é possível aprender no espaço da liberdade (FREIRE, 1997, p. 12).

Um outro grupo de respostas, com quatro citações, trata, diretamente, da figura dos estagiários enquanto regentes de aula. De acordo com os entrevistados, o fato de "ser estagiário" não representa a mesma figura e autoridade do professor titular:

Bom, na prática de ensino o principal motivo é porque você não é o professor efetivo, pois você chega como alguém que esta tomando posse, que eles nunca mais vão ver, então eles não precisam dar nenhum respeito a você. Você como estagiário o pessoal vai falar, ah, estagiário, beleza, a aula é nossa (ESTAGIÁRIO 4).

Ocorreram, ainda, quatro respostas que apontam a indisciplina como conseqüência da falta de identificação da escola pelo aluno, constituindo um processo de quebra dessa relação escola/aluno. $\mathrm{Na}$ opinião dos respondentes, a escola não consegue atingir as necessidades dos alunos impossibilitando-os de traçar quaisquer perspectivas de vida dentro desse contexto, gerando uma falta de interesse dos mesmos: "Para ele (aluno) o conteúdo não faz diferença. Não atinge ele, então para ele tanto faz. Porque o conteúdo está distante da realidade dele" (ESTAGIÁRIO 2).

Aquino (1996) reforça essa idéia ao propor que a escola ainda pressupõe o modelo educacional antigo, no qual o aluno se apresentava submisso e temeroso; quando, na verdade, o que temos é um novo aluno, um novo sujeito, num novo momento histórico, necessitando, assim, de novas propostas pedagógicas. Dessa forma, têm-se "[...] formas cristalizadas (escola) versus forças de resistência (alunos)" (AQUINO, 1996, p. 48).

Movimento, Porto Alegre, v. 14, n. 03, p. 117-137, setembro/dezembro de 2008. 
A dimensão moral das ações implica num posicionamento em relação aos valores e aos deveres. O ser humano, até certo ponto, é considerado como um ser livre, capaz de superar o determinismo da natureza, e com a possibilidade de fazer suas próprias escolhas. Assim, torna-se necessária a elaboração de critérios que classifiquem as ações como boas ou más, corretas ou inadequadas, e que orientem e justifiquem a escolha, que se configura como uma resposta diante das prescrições da sociedade. Cada ser humano posiciona-se diante de um conjunto de valores que não foram criados por ele isoladamente, mas no contexto das relações com outros seres humanos.

Diante dessas definições e das respostas dadas pelos estagiários, considera-se que há uma discrepância na dimensão moral dos alunos com a dimensão moral que a escola espera deles. A indisciplina, então, torna-se fruto de ações sem o senso crítico, ou seja, ações antiéticas, onde o certo ou errado não permeia uma relação de alteridade, mas de um interesse egocêntrico. A formação moral de alunos e de professores ou diretores das escolas parecem estar em choque.

Dessa forma, deve-se conhecer o contexto em que os alunos estão inseridos e os valores que eles defrontam cotidianamente. A partir disso, a escola deve promover discussões éticas para que o aluno se responsabilize pelas suas atitudes e que ele tome consciência do certo ou errado e entenda o motivo dessa relação.

Por fim, procurou-se identificar quais procedimentos que os estagiários utilizavam para minimizar a indisciplina. Com 8 citações, o procedimento mais utilizado foi a chantagem, sendo que, muitas vezes, esta apareceu sob o termo combinados, como nas citações:

\footnotetext{
Fazemos alguns castigos leves, tipo se falar palavrão não joga, fica um minuto no banco e depois volta (ESTAGIÁRIO 13).

A gente tenta fazer alguns combinados né, mas estes combinados, eu acho que acabam sendo meio que chantagem, tipo, a gente faz isso, então, vocês fazem aquilo (ESTAGIÁRIO 1).
}

Outro aspecto, referente aos procedimentos utilizados para conter a indisciplina, citado 6 vezes, foi a conversa. Nesse sentido, os estagiários afirmam que procuram dialogar com os alunos e, em alguns casos, até com a ajuda do professor titular.

Movimento, Porto Alegre, v. 14, n. 03, p. 117-137, setembro/dezembro de 2008. 
Já para 3 estagiários, o melhor procedimento é mostrar aos alunos que cumprir os combinados e as tarefas propostas dá a eles maior tempo de prática, podendo assim realizar mais tarefas:

\begin{abstract}
Eu tenho usado algumas dicas inclusive das pessoas que estão trabalhando comigo, que é jogar no fator tempo, fazer pensar a questão de que eles só têm 50 minutos de aula, e que se eles não aproveitarem, eles vão voltar para a sala de aula e terão que ficar mais tempo sentados calados. Não vão ter o momento de fazer atividades diferentes (ESTAGIÁRIO 5).
\end{abstract}

Aquino (1996) sugere algumas formas de atuação para a minimização da indisciplina escolar. A primeira refere-se à relação professor - aluno - conhecimento/ agente - clientela - objeto institucional. $\mathrm{O}$ autor acredita que o conhecimento deve ser o elemento central desta relação, assim, uma proposta fundamentada neste fator pode fundar e/ou resgatar a moralidade discente na medida em que seu trabalho pressupõe a observação de regras, de semelhanças e diferenças, de regularidades e exceções. Trata-se, então, dos modos de pensamentos envolvidos neste conhecimento e, não necessariamente, dos conteúdos em si.

A segunda sugestão ainda segue essa formulação teórica, porém, acrescenta a necessidade de desconstrução e reconstrução desse conhecimento junto com os alunos. Isso significa rever, continuamente, os conteúdos, as metodologias, as relações; estar em constante negociação com os presentes neste processo, sendo o aluno elemento essencial na construção dos parâmetros relacionais que ambos (alunos e professores) estão envolvidos.

\title{
4 ConsideraçõES FINAIS
}

O objetivo dessa pesquisa foi investigar as percepções e os significados para os estagiários de Educação Física em relação à indisciplina na escola.

A indisciplina sem dúvida é uma dificuldade apontada pelos estagiários. Na definição desses futuros professores, ela é um fenômeno caracterizado pelo não cumprimento das regras estabelecidas, e mesmo, pela falta de respeito para com professores e alunos. Além

Movimento, Porto Alegre, v. 14, n. 03, p. 117-137, setembro/dezembro de 2008. 
disso, sua manifestação adquiriu diversos contornos que vão de xingamentos a brigas durante as aulas.

Também é interessante destacar que, embora a indisciplina seja, de fato, um problema que aflige os estagiários, ela aparece adicionada a outras dificuldades, como a resistência dos alunos frente aos novos conteúdos e a falta de interesse/motivação dos alunos, sobretudo os que estudam no Ensino Médio.

Apesar dos estagiários identificarem a indisciplina como uma das dificuldades encontradas na prática pedagógica, descrevem o perfil do aluno disciplinado como aquele não passivo, que fala, questiona, crítica, além de apresentar respeito às regras.

Referente às causas da indisciplina, os estagiários apontam a ausência da base familiar no início da educação dos alunos, alertando para falta de autoridade e omissão na delimitação de limites por parte dos pais das crianças. Citam, também, as características da estrutura escolar que conserva os alunos por longos períodos imobilizados em carteiras, fatos que colaboram para a manifestação da indisciplina nas aulas de Educação Física, já que é um dos únicos momentos em que os alunos se sentem "livres".

Logo, de acordo com os estagiários respondentes, as manifestações da indisciplina nas aulas de Educação Física são diferentes das apresentadas nas demais disciplinas curriculares, isso porque as aulas acontecem em ambiente aberto, o que facilita a dispersão dos alunos. Apontam, também, que o contato físico das práticas e vivências intensifica a agressividade entre eles. Por fim, mencionam que a ausência de autoridade representada pela figura do estagiário pode contribuir na configuração de comportamentos indisciplinados.

No que diz respeito ao papel da escola frente à indisciplina, podemos perceber três alternativas nas falas dos estagiários: a eluciação das regras, direitos e deveres por meio da punição ou conscientização; a reinvenção do trabalho escolar com transformações que vão do planejamento à intervenção dos professores; e, por fim, o estabelecimento e incentivo de relações mais próximas entre escola e pais de alunos, possibilitando medidas em conjunto.

Em contrapartida, a maioria dos procedimentos metodológicos utilizados pelos estagiários permanece atrelado às concepções tradicionais

Wovimento, Porto Alegre, v. 14, n. 03, p. 117-137, setembro/dezembro de 2008. 
de educação, como, por exemplo, atitudes que envolvem chantagem e castigo.

Assim, diante destas constatações, não é possível supor a escola como uma instituição independente ou autônoma em relação às outras instituições, é inocente acreditar que o que ocorre no seu interior não tenha articulação aos movimentos exteriores a ela. Tal condição aponta para a necessidade de uma orientação mais fundamentada por parte dos docentes do Ensino Superior, proporcionando uma compreensão mais detalhada da indisciplina, e que, conseqüentemente, auxilie e viabilize a transformação desse problema por parte dos futuros professores.

Uma possibilidade apontada por Passos (1996) para facilitar a compreensão das questões da indisciplina na escola seria o conhecimento sobre a realidade escolar como um todo, por meio da imersão em seu cotidiano. Nesse sentido, os estudos do tipo etnográfico, nos quais se reconstrói os processos e relações do dia-a-dia escolar pela descrição detalhada dos fenômenos observados, viabilizariam investigações mais aprofundadas e coerentes em relação às questões da indisciplina na escola.

Além disso, o cotidiano escolar está permeado de valores que se traduzem em princípios, regras, ordens, proibições. O que se quer é que a ética aí encontre seu espaço, a fim de que se reflita sobre esses princípios (em que se fundamentam?), regras (qual sua finalidade?), ordens (a que interesses atendem?) e proibições (que resultado pretendem?), instalando-se ações/relações efetivamente democráticas. A ética é um eterno pensar, refletir, construir e, na escola, sua presença deve contribuir para que os alunos possam tomar parte dessa construção, serem livres e autônomos para pensar e julgar, para problematizar constantemente o viver pessoal e coletivo, fazendo o exercício da cidadania (BRASIL, 1998).

Assim, a manifestação do comportamento indisciplinado é conseqüência de diversos fatores que variam desde aspectos históricos até a prática pedagógica adotada pelo professor, sendo que o conhecimento das suas origens pode auxiliar o professor a intervir de forma mais eficaz no processo educacional.

Movimento, Porto Alegre, v. 14, n. 03, p. 117-137, setembro/dezembro de 2008. 
The perceptions and the meanings for the trainees of Physical Education regarding the indiscipline in the school

Abstract: This research investigated the perceptions and the meanings for the trainees of Physical Education regarding the indiscipline in the school. The methodology used was from qualitative nature, having as participants 16 students of a public course of Physical Education. The indiscipline was pointed by the trainees while a present problem in their practices and connected to different difficulties. Therefore, as methodological procedures more mentioned, appeared the blackmail, the agreements and the dialogue, being the school institution, outstanding while informative of the rules, of the rights and of the students' duties.

Keywords: Behavior. Physical Education. Education, primary and secondary.

Las percepciones y los significados para los practicantes de Educación Física en relación la indisciplina en la escuela

Resumen: Esta encuesta busco averiguar las percepciones y los significados para los practicantes de Educación Física en relación la indisciplina en la escuela. La metodologia utilizada fue de naturaleza calitativa, teniendo como participantes 16 alumnos de un curso de Licenciatura en Educación Física público. La indisciplina fue apuntada por los practicantes como um problema presente en sus prácticas y conectada a diferentes dificultades. Luego, como procedimientos metodológicos más mencionados aparecieron el chantaje, los combinados y el diálogo, siendo la institución escolar, destacada mientras elucidadora de las reglas, de los derechos y de los deberes de los alumnos.

Palabras-clave: Conducta. Educación Física. Educación primaria y secundaria.

\section{REFERÊNCIAS}

ALVES, C. M. S. D. (In)Disciplina na escola: cenas da complexidade de um cotidiano escolar. 2002. 176 f. Dissertação (Mestrado em Educação). Faculdade de Educação, UNICAMP, Campinas, 2002.

Movimento, Porto Alegre, v. 14, n. 03, p. 117-137, setembro/dezembro de 2008. 
AQUINO, J. G. A desordem na relação professor-aluno: indisciplina, moralidade e conhecimento. In:_ (Org). Indisciplina na escola: alternativas teóricas e práticas. São Paulo: Summus, 1996. p. 39-54.

BRASIL. Ministério de Educação e Cultura. Secretaria de Educação Fundamental. Parâmetros Curriculares Nacionais: terceiro e quarto ciclos - apresentação dos temas transversais. Brasília: MEC/ SEF, 1998.

FANTE, C. Bullying escolar: prevenção do problema começa pelo conhecimento. Jornal Unesp, Rio Claro, jul. 2006. p. 3.

FREIRE, J. B. Educação de corpo inteiro: teoria e prática da Educação Física. São Paulo: Scipione, 1997.

GASPARI, T. C.; SOUZA JUNIOR, O.; MACIEL, V.; IMPOLCETTO, F. M.; VENÂNCIO, L.; IORIO, L.; THOMMAZO, A.; DARIDO, S. C. A realidade dos professores de Educação Física na escola: suas dificuldades e sugestões. Revista Mineira de Educação Física, Viçosa, v. 14, n. 1, p. 109-137, 2006.

GOOD, T.; BROPHY, J. Looking in classroom. New York: Harper \& Row, 1978.

IMPOLCETTO, F. M. Alternativas para a questão da disciplina/ indisciplina nas aulas de Educação Física. 2000. 59 f. Trabalho de Conclusão de Curso (Graduação em Licenciatura em Educação Física) - Instituto de Biociências, Universidade Estadual Paulista, Rio Claro, 2000.

LA TAILLE, Y. A indisciplina e o sentido de vergonha. In: AQUINO, J. G. (Org). Indisciplina na escola: alternativas teóricas e práticas. São Paulo: Summus, 1996. p. 9-23.

LÜDKE, M.; ANDRÉ, M. E. D. Pesquisa em educação: abordagens qualitativas. São Paulo: EPU, 1986.

MARRACH, S. Informar não é o mesmo que formar. Jornal Unesp, Rio Claro, jul. 2006. p. 2.

PASSOS, L. F. A indisciplina e o cotidiano escolar: novas abordagens, novos significados. In: AQUINO, J. G. (Org). Indisciplina na escola: alternativas teóricas e práticas. São Paulo: Summus, 1996. p. 117-127.

PIERON, M. Didactica de las actividades físicas y desportivas. Madrid, Gymnos, 1988.

REGO, T. C. R. A indisciplina e o processo educativo: uma análise na perspectiva vygotskiana. In: AQUINO, J. G. (org). Indisciplina na escola: alternativas teóricas e práticas. São Paulo: Summus, 1996. p. 83-101.

TRIVIÑOS, A. S. Introdução à pesquisa em Ciências Sociais. São Paulo: Atlas, 1987.

Recebido em: 22/01/2008

Aprovado em: 14/02/2008

Movimento, Porto Alegre, v. 14, n. 03, p. 117-137, setembro/dezembro de 2008. 